\title{
Utility of posaconazole therapeutic drug monitoring and assessment of plasma concentration threshold for effective prophylaxis of invasive fungal infections: a meta-analysis with trial sequential analysis
}

\author{
Lu Chen, Yan Wang, Tao Zhang, Ying Li, Ti Meng, Leichao Liu, Ruifang Hao and Yalin Dong*
}

\begin{abstract}
Background: Posaconazole therapeutic drug monitoring (TDM) is increasingly used in clinical practice. However, the utility of posaconazole TDM and the target of posaconazole plasma concentration for clinical successful prophylaxis remain uncertain and controversial. The aim of this study was to evaluate posaconazole exposureresponse relationship and determine an optimum posaconazole concentration for prophylaxis against invasive fungal infections (IFIs).
\end{abstract}

Methods: Bibliographic databases were searched (from inception to September 2017) to select studies including the clinical outcomes below and above concentration cut-off value of $0.5 \mathrm{mg} / \mathrm{L}$ and $0.7 \mathrm{mg} / \mathrm{L}$. The reliability of the results were evaluated with trial sequential analysis (TSA).

Results: Twenty-eight studies with 1930 patients included were analyzed. The results of our pooled analysis demonstrated that patients with posaconazole plasma concentrations over $0.5 \mathrm{mg} / \mathrm{L}$ were twice more likely to achieve successful responses compared with those with lower concentrations (odds ratio, OR $=1.98,95 \%$ confidence interval, $\mathrm{Cl} 1.09-3.58, P=0.02)$ while the threshold, $0.7 \mathrm{mg} / \mathrm{L}$ showed no significant difference $(\mathrm{OR}=1.84$, $95 \% \mathrm{Cl} 0.94-3.63, P=0.08)$. The TSA results showed that there was sufficient information to support these findings.

Conclusions: An optimal posaconazole concentration target of $0.5 \mathrm{mg} / \mathrm{L}$ is suggested to ensure the clinical prophylactic efficacy and may help reduce the dosage and dose-dependent toxicity comparing with the target of $0.7 \mathrm{mg} / \mathrm{L}$.

Keywords: Posaconazole, Prophylaxis, Target plasma concentration, Invasive fungal infections, Therapeutic drug monitoring

\section{Background}

Invasive fungal infections (IFIs) are substantial causes of morbidity and mortality in immunocompromised hosts, such as patients with hematological malignancies and solid-organ transplant recipients [1]. Prophylaxis was widely accepted as an important intervention in this setting [2]. Posaconazole is a second-generation triazole agent with antifungal activity against a wide range of yeasts (candida species) and molds (Aspergillus species,

* Correspondence: dongyalin@mail.xjtu.edu.cn

Department of Pharmacy, The First Affiliated Hospital of Xi'an Jiaotong University, Xi'an 710061, China
Zygomycetes, and Fusarium species) [3, 4]. It has been strongly recommended as a prophylaxis of IFIs by guidelines from IDSA and ESCMID with high-quality evidence [5-7]. The US Food and Drug Administration (FDA) have approved three formulations, including the oral suspension, the recently delayed-release tablet and intravenous formulations. Due to the large interindividual variability in bioavailability and drug-drug interactions, therapeutic drug monitoring (TDM) is advised by IDSA and FDA in order to ensure adequate exposure and optimize clinical efficacy for posaconazole suspension $[5,8,9]$. 
The growing studies reported that there is a significant exposure-response relationship between posaconazole plasma concentrations and prophylactic efficacy [10-12]. Posaconazole TDM is also increasingly used in clinical practice to achieve a plasma concentration target of 0 . $5 \mathrm{mg} / \mathrm{L}$ at steady state which is equivalent to the minimum inhibitory concentration $\left(\mathrm{MIC}_{90}\right)$ of posaconazole for most Aspergillus spp. and was also recommended by the 4th European Conference on Infections in Leukaemia (ECIL-4) [13]. Thus, a stable drug concentration at $0.5 \mathrm{mg} / \mathrm{L}$ has been suggested in several posaconazole TDM studies [14-17]. Nevertheless, Jang et al. recommended a target at $0.7 \mathrm{mg} / \mathrm{L}$ which was also adopted in FDA document $[8,12]$. Meanwhile, posaconazole showed a good long-term safety profile compared with voriconazole and itraconazole [18-20]. Therefore, the utility of posaconazole TDM remains a controversial issue and most of related studies are limited by singlecenter practice and small sample size.

Although exposure-response relationship has been examined in several studies, it is still unclear whether TDM should be routinely performed during the process of posaconazole prophylaxis. Furthermore, there was no final consensus reached about posaconazole concentration target for prophylactic use to date. The aim of this study was to assess the relationship between posaconazole plasma concentration and clinical prophylactic efficacy and to define the optimum posaconazole concentration based on a meta-analysis.

\section{Methods}

\section{Search strategy}

We conducted a literature search in PubMed, EMBASE from inception to September 2017. A complementary manual literature search was performed by checking the reference lists in identified studies editorials, and related reviews. The 'key words' used were posaconazole, noxafil, concentration, exposure, efficacy, response, drug monitoring, pharmacovigilance, drug-related side effects and adverse reactions, drug eruptions. All searches were limited to human studies (see the detailed searching strategy in the Additional file 1).

\section{Selection criteria}

Two reviewers (LC, YW) independently evaluated each study and identified whether they met the predefined inclusion criteria. The methods in Systematic Reviews and Meta-Analyses (PRISMA) criteria were used for the search and flow of studies (Fig. 1). Inclusion criteria for eligible study: (i) concerned patients who received

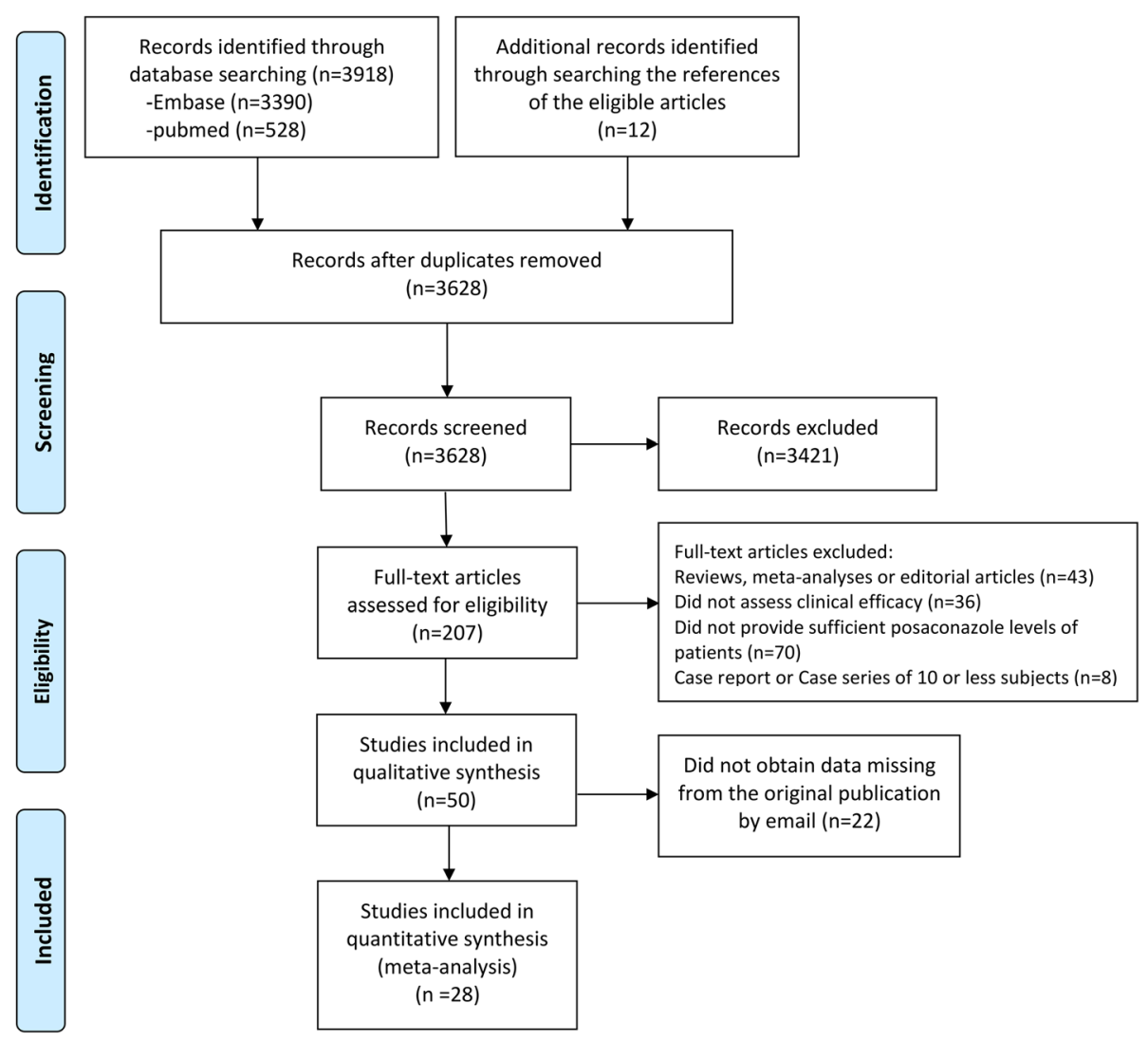

Fig. 1 Flow diagram of study selection 
posaconazole for prophylaxis of IFIs and reported posaconazole concentrations at steady state ( $\geq 7$ days) [21]; (ii) evaluated clinical efficacy or toxicity; (iii) provided the incidence of successful response at a given cut-off value; (iv) was an original article (not meta-analysis, review or editorial article); (v) was not case reports or case series of sample size $<10$ patients. (vi) used data derived from real patients rather than simulation results by models.

\section{Data extraction and quality assessment}

A broad range of data was extracted from each study into a spreadsheet by two investigators (LC, YW) independently, including year of publication, author, country, study design, sample size, baseline characteristics, and cut-off value, outcomes of interest and safety events. Disagreement on the specific data between two reviewers was resolved by discussion, with planned involvement of a third investigator (TZ) if consensus was not achieved. We contacted the authors to obtain data missing from the original publication by email when required.

Cochrane Collaboration's tool was applied to access the presence of sources of bias in randomized trials and the Newcastle-Ottawa Scale (NOS) was used for observational cohort and case-control studies [22, 23]. The NOS score ranges from 0 to 9 , with higher score associated with better quality and low risk of bias. We reported the risk of bias summary for each item for studies included.

\section{Statistical analysis}

We evaluated the exposure-response relationship between posaconazole plasma concentration and clinical efficacy for IFIs prevention. When the plasmas were measured at different sampling time, we chose the results measured near day 7 ( $\geq 7$ days). The cut-off values that defined the therapeutic and subtherapeutic levels were extracted and depended on each individual study. For each cut-off value, we compared the successful rates of IFIs prevention among patients with subtherapeutic posaconazole levels and those with therapeutic levels. Failure of prevention was defined as the incidence of breakthrough IFIs including possible, probable or proven IFIs according to the European Organization for Research and Treatment of Cancer/Invasive Fungal Infections Cooperative Group and the National Institute of Allergy and Infectious Diseases Mycoses Study Group (EORTC/ MSG) criteria [24]. The relationship between posaconazole concentration and clinical efficacy was assessed by $\mathrm{OR}$ values and confidence intervals. The Cochran $\mathrm{Q} \mathrm{X}^{2}$ test and $\mathrm{I}^{2}$ value were used to assess statistical heterogeneity, with a $P>0.1$ an $\mathrm{I}^{2}$ value of less than $50 \%$ indicates a low level of heterogeneity.

We performed subgroup analysis to determine if the threshold results were influenced by some factors including population type (children and adults), underlying disease (cardiothoracic transplantation and hematological malignancy). The cut-off values used in subgroup analysis depended on the original thresholds provided in each individual study. Odds ratios (ORs) and $95 \%$ confidence intervals (CIs) were not be able to report if the number of studies in each subgroup less than 2 or when the outcomes of interest were not evaluated (both successful rates were $100 \%$ or $0 \%$ in group with subtherapeutic levels or therapeutic posaconazole levels). We also performed a sensitivity analysis to examine whether the main results were impacted by excluding a single study or by excluding several studies which was examined with a specific standard, such as NOS score $\leq 6$, intervention following TDM results (intervention excluded), small sample size $(n<30$ excluded), IFIs diagnosed following EORTC/MSG criteria (studies without specific criteria excluded).

Trial sequential analysis (TSA) was conducted to evaluate the reliability of the result using TSA software (version 0.9.5.10 Beta, Copenhagen Trial Unit) [25]. TSA performs a cumulative meta-analysis, which creates a $\mathrm{Z}$ curve of the summarized observed effect (the cumulative number of included patients and events) and the monitoring boundaries for benefit, harm, and futility, and the required information size (RIS, the sample size needed in a meta-analysis to detect or reject a certain intervention effect) [26-29]. TSA boundaries were constructed to assess the risk of random error when the number of available participants is less than the RIS and the potential necessity for repeated updates [30]. If the $\mathrm{Z}$ curve of the cumulative meta-analysis crosses any of the boundary (including the TSA, futility or RIS curve), no further studies are required, and there is sufficient information to support the conclusions. We assumed a type I error of 5\% (two sides) and the power at $80 \%[27,28]$.

A $P$ value of $<0.05$ (two-sided) was considered statistically significant. Statistical analyses were performed using RevMan version 5.3 and Stata version 12.0 (Statacorp LP, College Station, TX).

\section{Results}

Study selection and characteristics of included studies Of the 3628 studies identified by the electronic and manual search, twenty-eight $[9,11,12,14,15,20,21,31-52]$ literatures were selected on the basis of inclusion criteria. The process of study selection is shown in Fig. 1. Table 1 summarized the characteristics of the final 28 studies 
Chen et al. BMC Infectious Diseases (2018) 18:155

Page 4 of 13

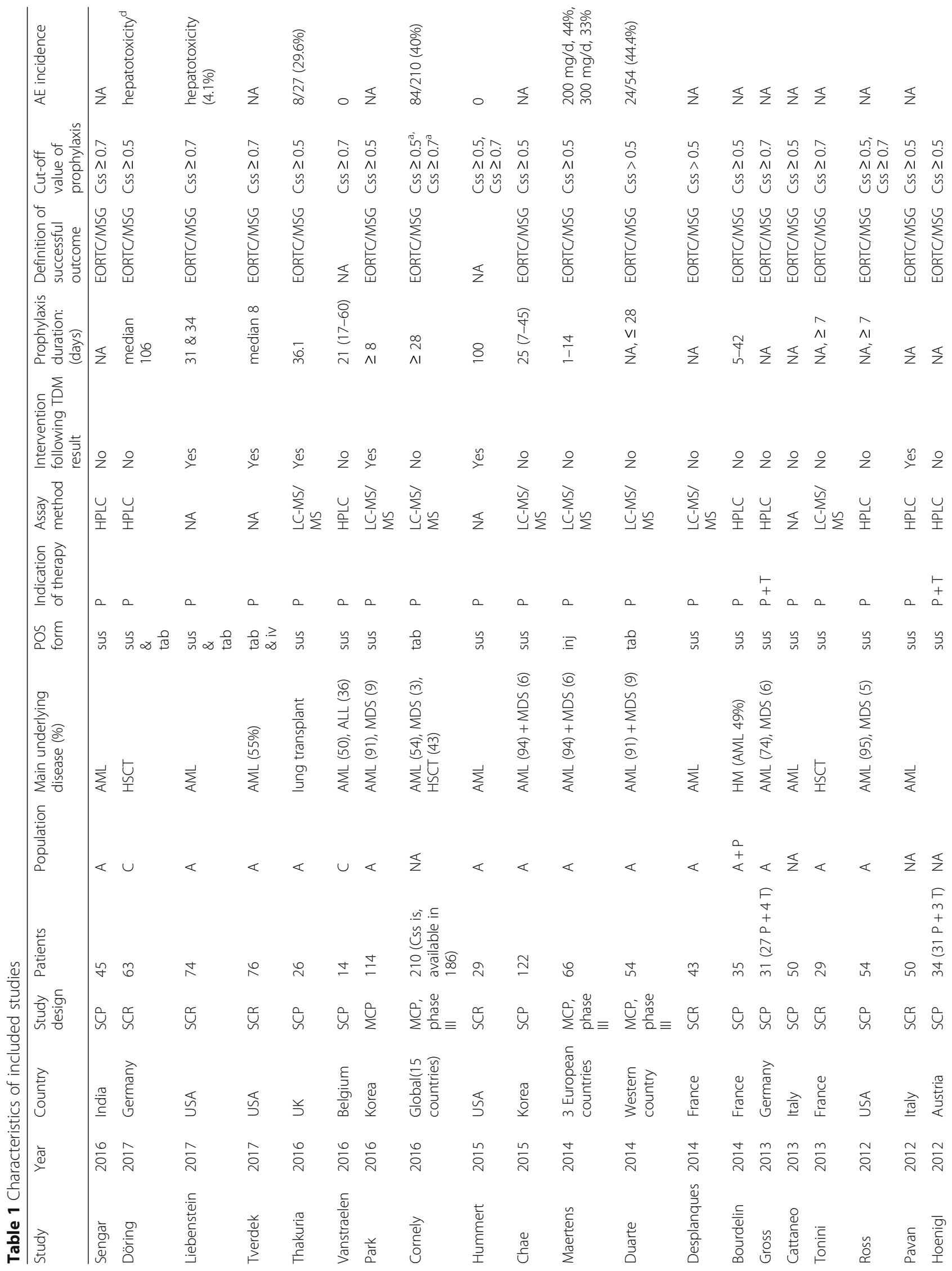


Chen et al. BMC Infectious Diseases (2018) 18:155

Page 5 of 13

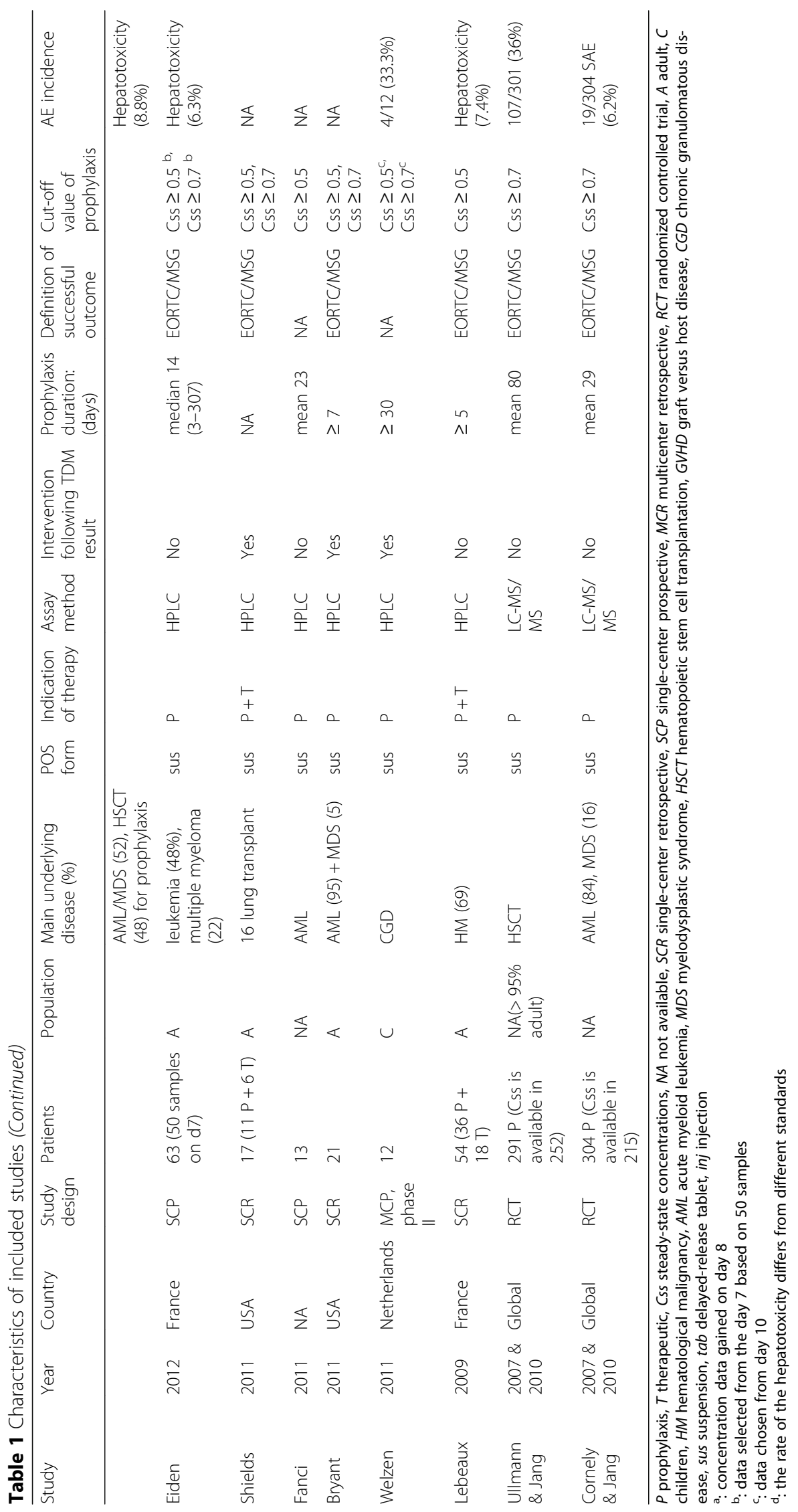


included in assessing the exposure-response relationships between posaconazole levels and efficacy of IFIs prevention. Patients in most of studies are adults, with only 3 studies included exclusively pediatric patients $[31,48,50]$. Two new posaconazole formulations, tablet and injection, were reported in 5 and 2 studies [34, 36, 37, 50-52], respectively. Four studies received posaconazole both for prophylaxis and treatment while the remaining studies merely used posaconazole for prevention [14, 15, 40, 45]. The majority of studies included patients with hematological malignancy, followed by cardiothoracic transplantation and other underlying disease with a high risk of fungal infection.

\section{Risk of bias}

The study quality was evaluated independently by two investigators (LC and WY). Observational studies $[9,11,14,15,31-52]$ were assessed for risk of bias using the NOS and were of moderate to high quality (Table 2). The Cochrane Collaboration's tool was used to assess risk of bias of two randomized controlled trial studies [20, 21] (Additional file 1: Figure S1).

\section{Evaluation of prophylactic efficacy}

All 28 [9, 11, 12, 14, 15, 20, 21, 31-52] studies, with 1930 enrolled patients, contributed to our systematic analysis of the relationship between posaconazole plasma concentration and rate of clinical prophylaxis success. Twenty participating studies $[9,11,14,15,32-39,41,43-48,50]$, with 1043 patients, provided outcomes of interest at a cut-off value of $0.5 \mathrm{mg} / \mathrm{L}$; and 15 studies [9, 12, 20, 21, 31, 34, 35, 40, 42, 43, 45, 47-49, 51, 52], with 1098 patients, provided data at a cut-off value of $0.7 \mathrm{mg} / \mathrm{L}$.

The overall pooled rate of successful prevention was $88.2 \%$ among 28 enrolled studies. The prophylactic threshold value was defined by each individual study at 0.5 and $0.7 \mathrm{mg} / \mathrm{L}$. As shown in Fig. 2, there was a significant difference at the cut-off value of $0.5 \mathrm{mg} / \mathrm{L}$ at which successful prophylactic outcome was achieved among $95.9 \%$ of patients with posaconazole concentrations $\geq 0$. $5 \mathrm{mg} / \mathrm{L}$ compared with $89.0 \%$ of those with concentrations $<0.5 \mathrm{mg} / \mathrm{L}(P=0.02)$. Patients with posaconazole plasma concentrations $\geq 0.5 \mathrm{mg} / \mathrm{L}$ had a significant chance of successful prophylaxis against IFIs about 2fold that of patients with concentrations $<0.5 \mathrm{mg} / \mathrm{L}$ $\left(\mathrm{OR}=1.98,95 \%\right.$ CI $\left.1.09-3.58, \mathrm{I}^{2}=0 \%\right)$.

Among studies reported at the cut-off value of $0.7 \mathrm{mg} /$ $\mathrm{L}$, patients with posaconazole concentrations $\geq 0.7 \mathrm{mg} / \mathrm{L}$ had a rate of successful prophylactic outcome similar to that of those with concentrations $<0.7 \mathrm{mg} / \mathrm{L}(95.8 \%$ versus $90.3 \%)(P=0.08)$ (Fig. 3).

No statistically significant difference was observed at this threshold although OR value was calculated as 1.84 (95\% CI 0.94-3.63, $\mathrm{I}^{2}=0 \%$ ).

\section{Subgroup analysis}

A summary of subgroup analysis for prophylactic efficacy was shown in Table 3. Three studies included pediatric patients but the successful rates appeared to be $100 \%$ or $0 \%$ which make the OR values not estimable between two research groups $[31,48,50]$. Thus, the predesigned subgroup of population type (children and adults) could not be analyzed due to limited relevant research.

For the cut-off value of $0.5 \mathrm{mg} / \mathrm{L}$, successful outcomes of patients with hematological malignancy presented significant difference among those with therapeutic and subtherapeutic levels while there was no statistical significance for cardiothoracic transplant recipients (34 lung transplantations and 1 heart transplantations) ( $P=$ 0.02 and $P=0.97$, respectively). For cut-off value of 0 . $7 \mathrm{mg} / \mathrm{L}$, neither group showed a significant difference $(P$ $=0.09$ and $P=0.66$, respectively).

\section{Publication bias and sensitivity analysis}

We evaluated publication bias at the steady-state concentration cut-off value of $0.5 \mathrm{mg} / \mathrm{L}$ (20 studies) and 0 . $7 \mathrm{mg} / \mathrm{L} 15$ studies) prophylaxis. The results of funnel plots seemed asymmetric under cut-off value of $0.5 \mathrm{mg} /$ L. (Fig. 4). However the Harbord's test $(P=0.16$ and 0.26 under cut-off value of 0.5 and $0.7 \mathrm{mg} / \mathrm{L}$ ) showed a low likelihood of publication bias.

Results of sensitivity analysis showed that the main results of meta-analysis were relatively stable after excluding each single study enrolled under both cut-off values (Additional file 1: Figure S2). Similarly, no change in effect was found when studies were analyzed by NOS score $\leq 6$ [33, 35, 41, 44, 52], intervention following TDM results (intervention excluded) [32, 33, 35, 44, 45, 47, 48, 51, 52], small sample size ( $n<30$ excluded) [31, 32, 35, 42, 45-48], and IFIs diagnosed following EORCT/MSG criteria (studies without specific criteria excluded) [31, 35, 46, 48], except for a significant change after excluding studies from Liebenstein [51] and Tverdek [52] (Additional file 1: Table S1).

\section{Trial sequential analysis}

TSA was performed in our study to analyze whether the available data were powered enough to reach firm conclusions in the present study. For the posaconazole concentration target of $0.5 \mathrm{mg} / \mathrm{L}$, TSA showed that it could benefit more on the prevention successful rate when a posaconazole level is more than $0.5 \mathrm{mg} / \mathrm{L}$, as the number of patients evaluated for this breakpoint $(n=1043)$ surpassed the optimal sample sizes $(n=455)$ (Fig. 5a). Although there was some fluctuation before the $Z$ curve reaching the RIS, the $Z$ curve remained outside of the conventional benefit boundary after crossing the RIS. For the posaconazole target of $0.7 \mathrm{mg} / \mathrm{L}$, TSA showed that patients with posaconazole level over $0.7 \mathrm{mg} / \mathrm{L}$ 
Table 2 Newcastle-Ottawa scoring of studies assessing efficacy

\begin{tabular}{|c|c|c|c|c|c|c|c|c|c|}
\hline Study & $\begin{array}{l}\text { Representativeness } \\
\text { of the exposed } \\
\text { cohort }\end{array}$ & $\begin{array}{l}\text { Selection of } \\
\text { the non- } \\
\text { exposed } \\
\text { cohort }\end{array}$ & $\begin{array}{l}\text { Ascertainment } \\
\text { of exposure }\end{array}$ & $\begin{array}{l}\text { Outcome of } \\
\text { intferest was } \\
\text { not present } \\
\text { at start }\end{array}$ & $\begin{array}{l}\text { Comparability } \\
\text { (score } 0,1 \text { or } 2 \text { ) }\end{array}$ & $\begin{array}{l}\text { Assessment } \\
\text { of outcome }\end{array}$ & $\begin{array}{l}\text { Sufficient } \\
\text { follow-up } \\
\text { of } \\
\text { outcome }\end{array}$ & $\begin{array}{l}\text { Adequacy } \\
\text { of follow } \\
\text { up of } \\
\text { cohorts }\end{array}$ & Score \\
\hline Thakuria, L., et al. & NA & 1 & 1 & 1 & 1 & 1 & 1 & 1 & $7 / 9$ \\
\hline Vanstraelen, K., et al. & 1 & 1 & 1 & 1 & 1 & 0 & 1 & 1 & $7 / 9$ \\
\hline Park, W. B., et al. & 1 & 1 & 1 & 1 & 1 & 1 & NA & 0 & $6 / 9$ \\
\hline Cornely, O. A., et al. & 1 & 1 & 1 & 1 & 2 & 1 & 1 & 1 & $9 / 9$ \\
\hline Hummert, S. E., et al. & NA & 1 & 0 & 1 & 1 & 0 & 1 & 1 & $5 / 9$ \\
\hline Chae, H., et al. & 1 & 1 & 1 & 1 & 1 & 1 & 1 & 1 & $8 / 9$ \\
\hline Maertens, J., et al. & 1 & 1 & 1 & 1 & 1 & 1 & 1 & 1 & $8 / 9$ \\
\hline Duarte, R. F., et al. & 1 & 1 & 1 & 1 & 1 & NA & 1 & 1 & $7 / 9$ \\
\hline Desplanques, P. Y., et al. & NA & 1 & 1 & 1 & 1 & 1 & 1 & 1 & $7 / 9$ \\
\hline Bourdelin, M., et al. & 1 & 1 & 1 & 1 & 1 & 1 & 1 & 1 & $8 / 9$ \\
\hline Gross, B. N., et al. & 1 & 1 & 1 & 1 & 1 & 1 & 1 & 1 & $8 / 9$ \\
\hline Cattaneo, C., et al. & NA & 1 & 0 & 1 & 1 & NA & 1 & 1 & $5 / 9$ \\
\hline Tonini, J., et al. & 1 & 1 & 1 & 1 & 1 & 1 & 1 & 1 & $8 / 9$ \\
\hline Ross, A. L., et al. & NA & 1 & 1 & 1 & 1 & 1 & 1 & 1 & $7 / 9$ \\
\hline Pavan, L., et al. & NA & 1 & 1 & 1 & 1 & NA & 1 & 1 & $6 / 9$ \\
\hline Hoenigl, M., et al. & 1 & 1 & 1 & 1 & 1 & 1 & 1 & 1 & $8 / 9$ \\
\hline Eiden, C., et al. & 1 & 1 & 1 & 1 & 0 & 1 & 1 & 1 & $7 / 9$ \\
\hline Shields, R. K., et al. & 1 & 1 & 1 & 1 & 1 & 1 & 1 & 1 & $8 / 9$ \\
\hline Fanci, R., et al. & 1 & 1 & 1 & 1 & 1 & 0 & 1 & 1 & $7 / 9$ \\
\hline Bryant, A. M., et al. & NA & 1 & 1 & 1 & 1 & 1 & 1 & 1 & $7 / 9$ \\
\hline Welzen, M. E., et al. & 1 & 1 & 1 & 1 & 1 & 0 & 1 & 1 & $7 / 9$ \\
\hline Lebeaux, D., et al. & NA & 1 & 1 & 1 & 1 & 1 & 1 & 1 & $7 / 9$ \\
\hline Sengar & 1 & 1 & 1 & 1 & 0 & 1 & 1 & 1 & $7 / 9$ \\
\hline Döring & 1 & 1 & 1 & 1 & 1 & 1 & 1 & 1 & $8 / 9$ \\
\hline Liebenstein & 1 & 1 & NA & 1 & 2 & 1 & NA & 1 & $7 / 9$ \\
\hline Tverdek & 1 & 1 & NA & 1 & 1 & 1 & NA & 1 & $6 / 9$ \\
\hline
\end{tabular}

NA not available

did not show significant priority on the successful prevention rate comparing with those with lower than $0.7 \mathrm{mg} / \mathrm{L}$. With the all the available data included, the number of patients evaluated for this breakpoint $(n=$ 1098) also surpassed the optimal sample sizes $(n=$ 693) for the same outcome (Fig. 5b). However, it should be noted that the $\mathrm{Z}$ curve turned to be out of the conventional boundary after adding three recent studies in our analysis $[31,49,51]$.

\section{Discussion}

This meta-analysis was designed to assess the exposureresponse relationship between the reported posaconazole concentration and clinical prophylactic efficacy. Our pooled analysis demonstrated that a steady-state posaconazole target of $\geq 0.5 \mathrm{mg} / \mathrm{L}$ is more predictive for successful prophylaxis than the target of $\geq 0.7 \mathrm{mg} / \mathrm{L}$. The results indicated that with posaconazole levels at $0.5 \mathrm{mg} / \mathrm{L}$ or higher, patients with hematological malignancies were twice more likely to achieve a successful prophylaxis.

We considered possible IFI as failed prevention because patients are usually enrolled in empirical treatment programs once they were diagnosed as possible IFIs. An ideal prophylaxis should prevent even a possible IFI result which could probably degenerate into probable or even proven and cause more medical costs and prolonged hospitalizations $[5,6]$. Before our pooled analysis, there were two putative targets of steady state plasma, 0 . $5 \mathrm{mg} / \mathrm{L}$ and $0.7 \mathrm{mg} / \mathrm{L}$, which were suggested as threshold levels for IFIs prophylaxis. The first target of $0.5 \mathrm{mg} /$ $\mathrm{L}$ is based on the $\mathrm{MIC}_{90}$ for most Aspergillus species [23] and the second target of $0.7 \mathrm{mg} / \mathrm{L}$, is considered the efficacy threshold by the FDA. [24] The evidence of the recommendation from FDA is based on a RCT trial in high 


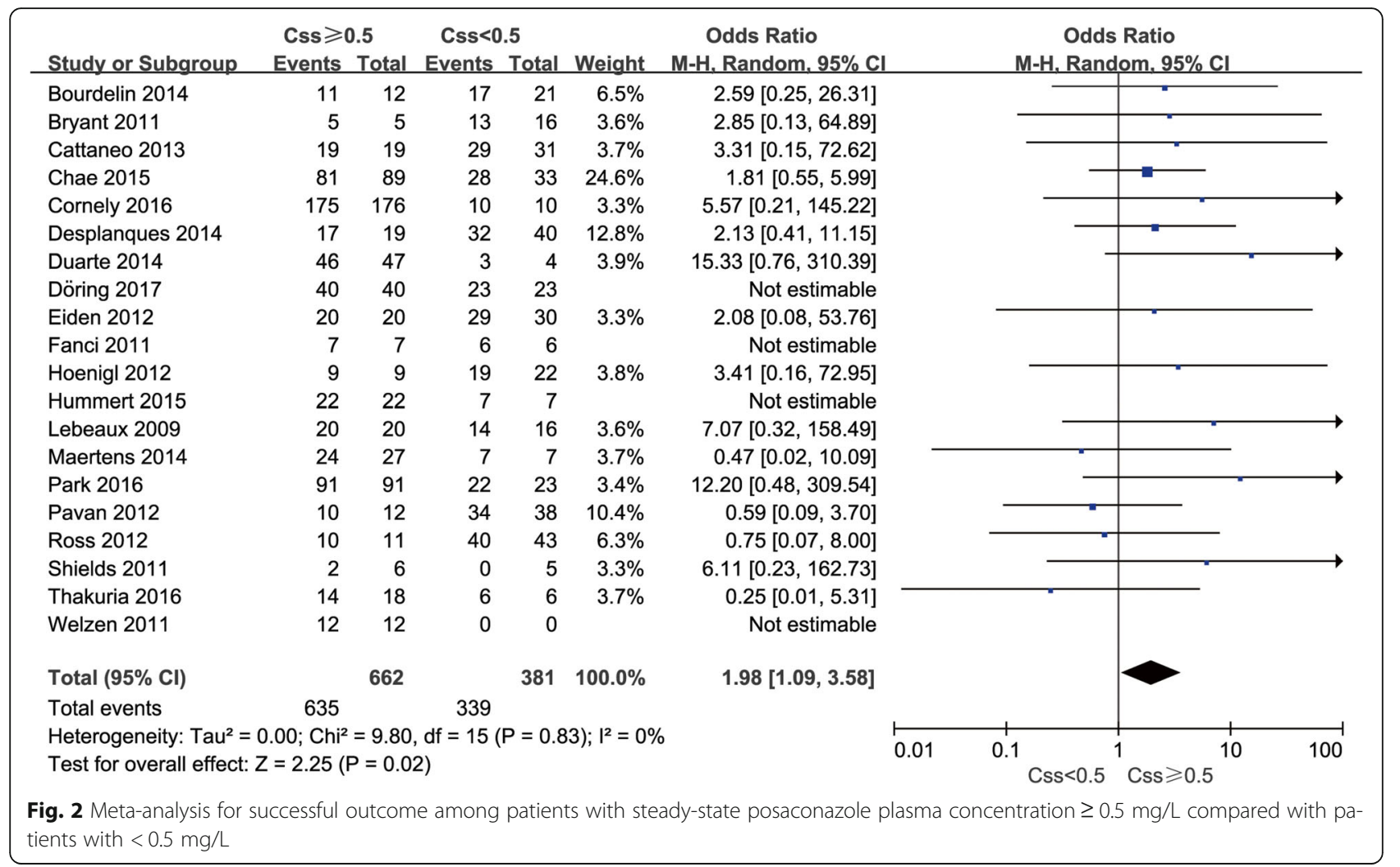

risk patients with graft versus host disease (GVHD) after allogeneic hematopoietic stem cell transplantation (alloHSCT) and the results showed that the successful prophylactic rate would be $98.1 \%$ when patients' posaconazole average concentration reached over $0.7 \mathrm{mg} / \mathrm{L}$, which is similar to our outcome $(95.8 \%)$ [12, 21]. Ullmann et al. used the average posaconazole concentrations while most of our data were from trough concentrations which are more available in clinical practice [21]. As usual, the posaconazole average concentration is higher than the

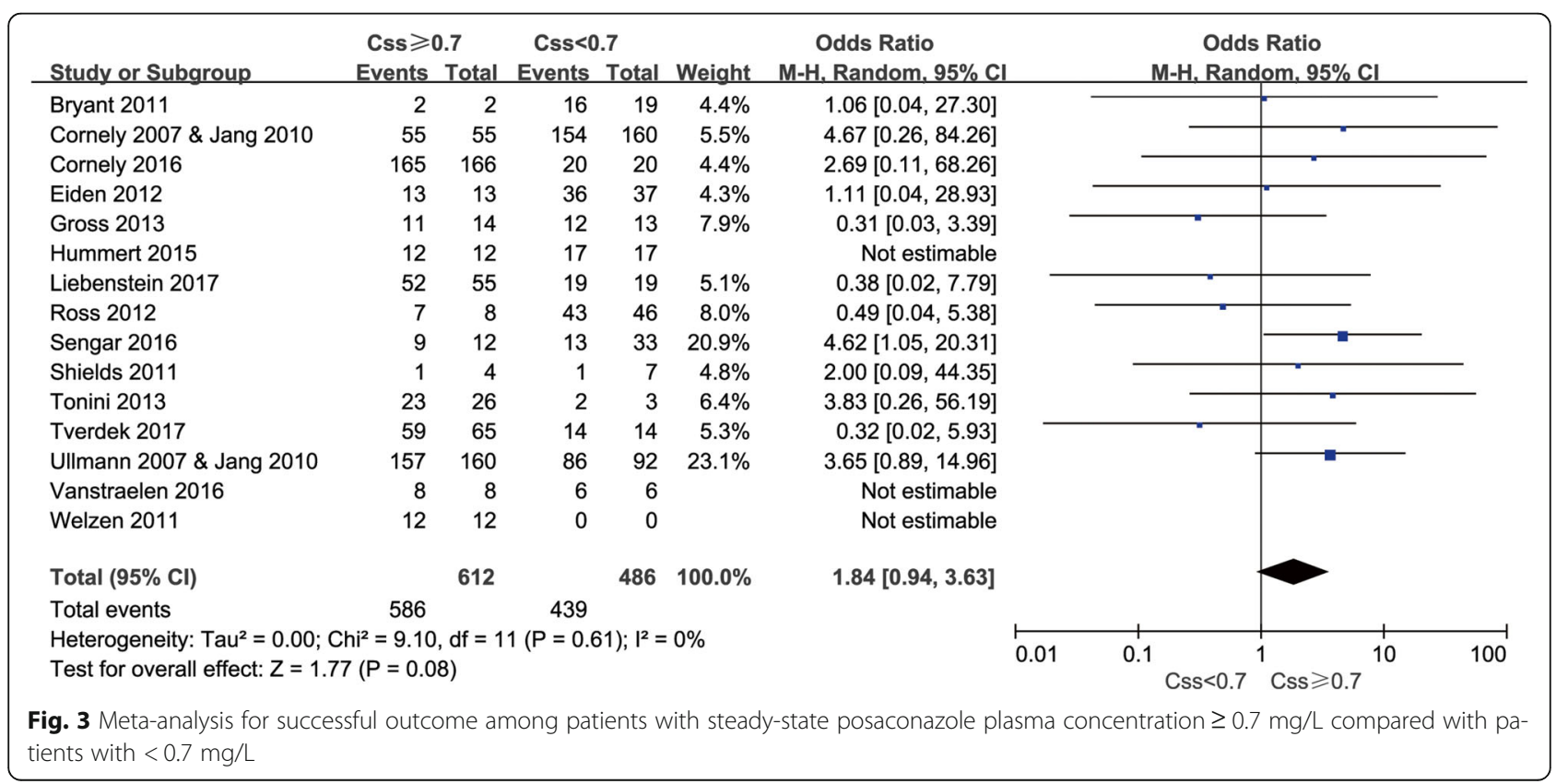


Table 3 Summary of subgroup analysis for prophylaxis efficacy

\begin{tabular}{|c|c|c|c|c|c|c|c|c|}
\hline Subgroup & & $\begin{array}{l}\text { Cut-off } \\
\text { value(mg/L) }\end{array}$ & OR(95\% Cl) & $\begin{array}{l}\text { No. of } \\
\text { studies }\end{array}$ & $\begin{array}{l}\text { No. of participants in } \\
\text { experimental group }\end{array}$ & $\begin{array}{l}\text { No. of participants in } \\
\text { control group }\end{array}$ & $1^{2} \%$ & $P$ \\
\hline \multirow[t]{2}{*}{$\begin{array}{l}\text { Underlying } \\
\text { disease }\end{array}$} & $\begin{array}{l}\text { Cardiothoracic } \\
\text { transplant }\end{array}$ & $\begin{array}{l}\text { Css } \geq 0.5 \text { vs. } \\
\text { Css }<0.5\end{array}$ & $1.16[0.05,26.94]$ & 2 & $16 / 24$ & $6 / 11$ & 49 & 0.92 \\
\hline & $\begin{array}{l}\text { Hematological } \\
\text { malignancy }\end{array}$ & $\begin{array}{l}\text { Css } \geq 0.5 \text { vs. } \\
\text { Css }<0.5\end{array}$ & $2.06[1.12,3.82]$ & 18 & $619 / 638$ & $333 / 370$ & 0 & 0.02 \\
\hline \multirow[t]{2}{*}{$\begin{array}{l}\text { Underlying } \\
\text { disease }\end{array}$} & $\begin{array}{l}\text { Cardiothoracic } \\
\text { transplant }\end{array}$ & $\begin{array}{l}\text { Css } \geq 0.7 \text { vs. } \\
\text { Css }<0.7\end{array}$ & $2.00[0.09,44.35]$ & 1 & $1 / 4$ & $1 / 7$ & NA & 0.66 \\
\hline & $\begin{array}{l}\text { Hematological } \\
\text { malignancy }\end{array}$ & $\begin{array}{l}\text { Css } \geq 0.7 \text { vs. } \\
\text { Css }<0.7\end{array}$ & $1.84[0.92,3.68]$ & 14 & $585 / 608$ & $438 / 479$ & 0 & 0.09 \\
\hline
\end{tabular}

NA not available

trough concentration although there is no significant fluctuation after steady state [19]; thus, it is reasonable that an average level of $0.7 \mathrm{mg} / \mathrm{L}$ could be considered as the threshold in Jang's study and a lower trough level at 0 . $5 \mathrm{mg} / \mathrm{L}$ in our analysis [12].

It has been reported that IFIs are associated with high morbidity and mortality in patients with hematological malignancy $[5,6,14]$. Our study demonstrated that performing TDM could help posaconazole concentrations reach the threshold $0.5 \mathrm{mg} / \mathrm{L}$ and then improve the successful rate from $89.0 \%$ (95\% CI $87.4 \%-90.6 \%)$ to $95.9 \%$ (95\% CI 95.2\%-96.7\%) for prophylactic usage. The successful rate will also be improved from 90.3\% (95\% CI $89.0 \%-91.7 \%$ ) to $95.8 \%$ (95\% CI $94.9 \%-96.6 \%$ ) if the posaconazole concentration reached at $0.7 \mathrm{mg} / \mathrm{L}$ or higher, yet there was no statistical significance. The possible explanation of this result is that patients with posaconazole stable concentration at the range of $0.5-0$. $7 \mathrm{mg} / \mathrm{L}$ were mostly identified as a successful prevention; thus, the target of $0.7 \mathrm{mg} / \mathrm{L}$ was evaluated with no significance. Additionally, it has been proved that posaconazole concentrations in pulmonary alveolar cells are over 40-fold higher than those in plasma [53]. So the high posaconazole aggregation pulmonary could be explicable for achieving satisfactory effects under low posaconazole plasma levels.

For the result of subgroup analysis based on the underlying disease, a target of $0.5 \mathrm{mg} / \mathrm{L}$ on the steady state is recommended in patients with hematological malignancies but not for cardiothoracic transplant recipients. There was only one study involved in the solidorgan transplant group at the target of $0.7 \mathrm{mg} / \mathrm{L}$, so whether $0.7 \mathrm{mg} / \mathrm{L}$ could be a target of this cardiothoracic transplant population still need further studies to confirm. Our results showed that the prophylactic efficacy have no significant difference when patients' posaconazole levels were over or below $0.7 \mathrm{mg} / \mathrm{L}$ in cardiothoracic transplant recipients. The chief reasons are that posaconazole concentrations of this population showed great variability [32] and studies on this population are limited at present. Therefore, the utility of TDM in cardiothoracic transplant recipients and the specific posaconazole target warrant further investigation.

Both heterogeneity and the publication bias in our pooled analysis are low. Sensitivity analysis was done by exclusion of studies with NOS $\leq 6$, intervention following TDM results and small sample size with $n<30$. It shows that the significance of main outcome at $0.5 \mathrm{mg} / \mathrm{L}$
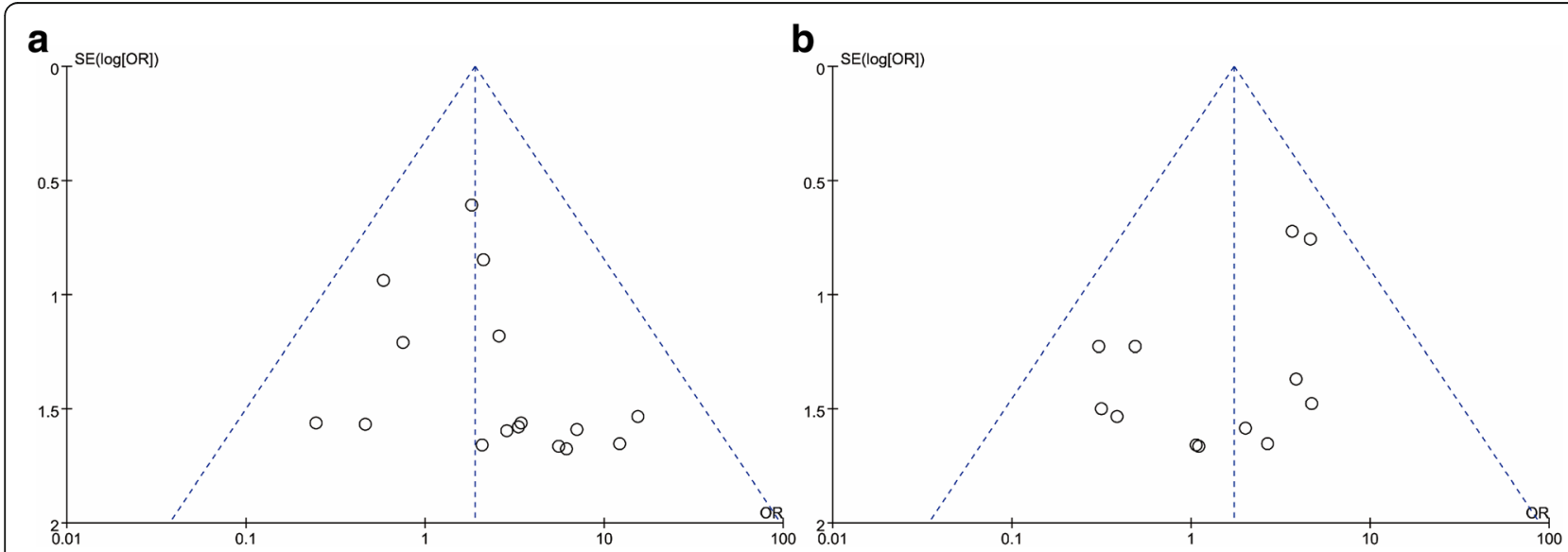

Fig. 4 Funnel plots for the cut-off value of $0.5 \mathrm{mg} / \mathrm{L}$ (a) and $0.7 \mathrm{mg} / \mathrm{L}$ (b) 


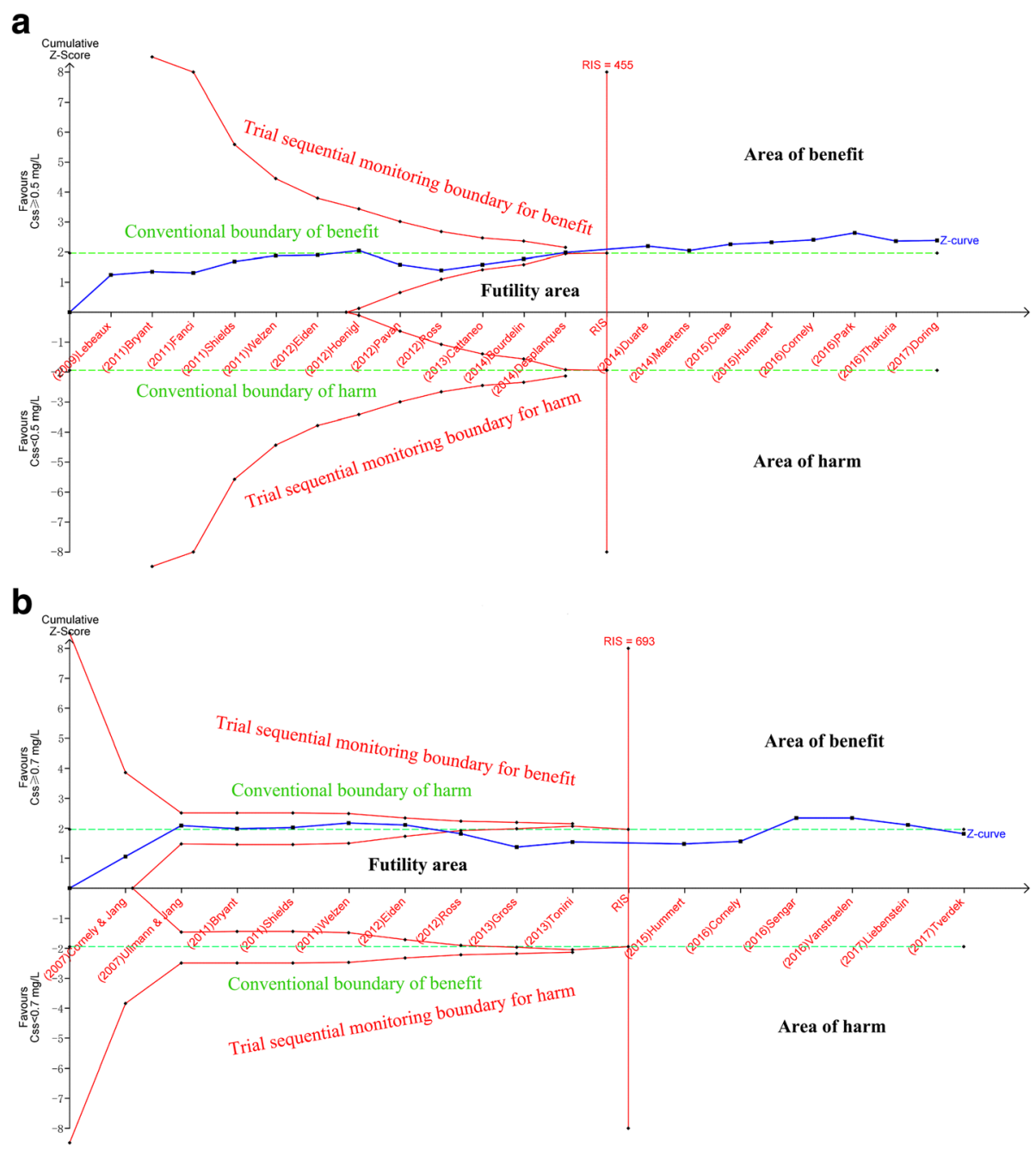

Fig. 5 The results of trial sequential analysis under two posaconazole TDM targets. a Trial sequential analysis in 20 trials for posaconazole concentration target of $0.5 \mathrm{mg} / \mathrm{L}$. The required information size (RIS, i.e., number of participates) was calculated as 455 . The $Z$ curve crossed the conventional boundary of benefit and the vertical line of RIS. b Trial sequential analysis in 15 trials for posaconazole concentration target of $0.7 \mathrm{mg} / \mathrm{L}$. The RIS was calculated as 693 . The $Z$ curve crossed the futility boundary and the vertical line of RIS

remained stable after excluding studies mentioned above or removing each individual study, which confirmed the high reliability and stability of our meta-analysis. However, after excluding 6 studies following TDM intervention $[35,45,47,48,51,52]$, the insignificant outcome $(P$ $=0.08)$ of the target at $0.7 \mathrm{mg} / \mathrm{L}$ turned into significant $(P=0.03)$. This change might attribute to the influence of dosing adjustment, which could interfere the standard-compliant samples or the prevention outcome.

A particular section of our meta-analysis was the result verification using of TSA. According to the TSA results, it is noticeable that the $\mathrm{Z}$ curves were not stable with the growing data. For the TSA result of $0.7 \mathrm{mg} / \mathrm{L}$, the $\mathrm{Z}$ curve escaped out of the conventional boundary even after reaching the optimal sample size. Study from Sengar was supposed to be the main reason contributing to this reverse change because the $\mathrm{Z}$ curve turned back to the conventional boundary after adding the other two studies (Vanstraelen and Liebenstein) into the analysis. However, only the abstract is available in Sengar's study and maybe the race of the participants (Asian) could be a possible reason to explain this result. In brief, the TSA results under two posaconazole concentration targets indicated that there are sufficient information to support our conclusion. However, only two RCTs are available in our study, a well-designed prospective trial is needed to verify our results.

According to the involved studies, we found that posaconazole concentration is higher when patients are administered with those two new formulations, delayedrelease tablet and injection formulation due to the stable bioavailability [5]. Thus, the number of patients with 
subtherapeutic levels is less and there were five and two studies involved in groups of tablet and injection in our analysis, respectively. Since posaconazole delayed-release tablet and the injection forms could increase the possibility of achieving the target, whether TDM is useful in this case still needs future investigation with large sample size. To date, posaconazole oral suspension formulation is still widely used and remains available worldwide, and this form is still an important option for patients with nasogastric tubes or those unable to take tablets [11]. Therefore, the target of $0.5 \mathrm{mg} / \mathrm{L}$ is required and should be recommended during the TDM process for patients administered with posaconazole oral suspension.

It was reported that posaconazole showed a good safety profile during a standard long-term administration. The most common adverse event which related to the treatment is gastrointestinal tract disturbances $[20,54,55]$ and the incidence of serious adverse events is $6 \%-13 \%$, including the hepatotoxicity, QTc prolongation, etc. $[20,21]$. Thus, studies about the relationship between posaconazole exposure and adverse events are still limited, which make it not viable to explore the threshold for safety concentration like voriconazole [56, 57]. To date, posaconazole appears to have a more favorable safety and tolerability profile than voriconazole $[58,59]$. Only a few studies accessed the relationship between posaconazole exposure and treatment efficacy, which make it infeasible to define a posaconazole concentration target by meta-analysis. Walsh et al. conducted a study in which a cohort of 67 patients who received posaconazole for salvage treatment of invasive Aspergillosis, the results demonstrated that the cure rates increased with growing posaconazole average concentration quartiles. The cure rates could achieve $75 \%$ when posaconazole average concentration reached at 1 . $25 \mathrm{mg} / \mathrm{L}$; thereby this quartile value was subsequently accepted as a threshold for IFIs treatment. Further research like a prospective and well-powered study is required to investigate the optimum posaconazole concentration for ensuring safety of posaconazole and efficacy of salvage therapy.

\section{Strengths and weaknesses}

Our study has several strengths. This is the first pooled analysis comparing two commonly used but disputed cut-off values for prophylactic efficacy of posaconazole and the results recommended an optimal target for posaconazole usage in IFIs prevention. Besides, we implemented subgroup analysis to seek the suitable targets for patients in different underlying diseases. Our results recommended $0.5 \mathrm{mg} / \mathrm{L}$ as a target concentration for IFIs prophylaxis in patients with hematological malignancy, which is more likely to achieve than $0.7 \mathrm{mg} / \mathrm{L}$; hence, it may help to reduce the posaconazole dosage and financial burden for patients and simultaneously ensure the prophylactic efficacy in the long-term usage of posaconazole.

Potential limitations of our study merit discussion. First, we did not investigate the relationship between treatment efficacy, safety and posaconazole exposure owing to the limited number of published studies. Second, survival benefit on each cut-off values have not been explored due to the low mortality and short follow-up time of studies involved. Third, studies concerning the direct comparison of the clinical outcomes of patients taking posaconazole for prophylaxis of IFI with and without TDM are limited, so we are not able to validate the practical benefit of posaconazole TDM in clinical up to date. Further studies are needed in this respect. Finally, the inevitable limitation of all meta-analysis is that the quality of the results are directly related to the quality of individual studies included in the analysis. Except for two randomized controlled trials, all were cohort studies, many of which used a small sample size and focused on a single center. However, we provide the largest pooled analysis of the relationship between posaconazole TDM and clinical efficacy of IFIs prevention. The present study highlights high quality studies in this area is poor and emphasizes the remaining controversy regarding the relationship between posaconazole TDM and treatment efficacy and safety. A welldesigned prospective trial to assess the utility of posaconazole TDM, especially in reference to survival, successful response and toxicity, is warranted.

\section{Conclusion}

TDM of posaconazole prophylaxis with the oral suspension has been increasingly used and therefore recommendations regarding target plasma are urgent needed. Based on the results from our meta-analysis, we conclude that patients with posaconazole plasma concentrations $\geq 0.5 \mathrm{mg} / \mathrm{L}$ are associated with an increased probability of successful IFIs prevention exclusively for those with hematological malignancies. Our study highlights the lack of the studies regarding the relationship between TDM and clinical outcome in the newly released formulations: tablet and injection of posaconazole.

\section{Additional file}

Additional file 1: Table S1. Summary of sensitive analysis for prophylaxis efficacy. Figure S1. Source of bias in two randomized trials following Cochrane Collaboration's tool. Figure S2. Sensitive analysis of 
individual study involved at cut-off value of $0.5 \mathrm{mg} / \mathrm{L}$ (A) and $0.7 \mathrm{mg} / \mathrm{L}$ (B). Statement for detailed searching strategy. (PDF $301 \mathrm{~kb}$ )

\section{Abbreviations}

A: Adult; allo-HSCT: Allogeneic hematopoietic stem cell transplantation; AML: Acute myeloid leukemia; C: Children; CGD: Chronic granulomatous disease; Cl: Confidence interval; Css: steady-State concentrations; ECIL: European Conference on Infections in Leukaemia; EORTC/ MSG: European Organization for Research and Treatment of Caner/Invasive Fungal Infections Cooperative Group and the National Institute of Allergy and Infectious Diseases Mycoses Study Group; ESCMID: European Congress of Clinical Microbiology and Infectious Diseases; FDA: Food and Drug Administration; GVHD: Graft versus host disease; HM: Hematological malignancy; IDSA: Infectious Diseases Society of America; IFIs: Invasive fungal infections; inj: Injection; MCR: Multicenter retrospective; MDS: Myelodysplastic syndrome; NA: Not available; NOS: Newcastle-Ottawa Scale; OR: Odds ratio; P: Prophylaxis; RCT: Randomized controlled trial; RIS: Required information size; SCP: Single-center prospective; SCR: Single-center retrospective; sus: Suspension; T: Therapeutic; tab: Delayed-release tablet; TDM: Therapeutic drug monitoring; TSA: Trial sequential analysis

\section{Acknowledgements}

Not applicable.

\section{Funding}

This work was supported by the National Natural Science Foundation of China [grant numbers 81672954] and the Chinese Medical Association [grant number 16010120628].

\section{Availability of data and materials}

All data generated or analyzed during this study are included in this published article [and its additional files].

\section{Authors' contributions}

Conceived and designed the protocol: LC, YLD. Execution of search strategy and data extraction: LC, YW. Data analysis and interpretation: LC, YW, TZ, LCL, RFH. Drafting manuscript: LC, YL, TM. All authors have read and approved the final manuscript.

\section{Ethics approval and consent to participate}

No ethical approval was sought, because approval was deemed unnecessary for this meta-analysis.

\section{Consent for publication}

Not applicable.

\section{Competing interests}

The authors declare that they have no competing interests.

\section{Publisher's Note}

Springer Nature remains neutral with regard to jurisdictional claims in published maps and institutional affiliations.

Received: 31 October 2017 Accepted: 21 March 2018

Published online: 02 April 2018

\section{References}

1. Drew RH, Townsend ML, Pound MW, et al. Recent advances in the treatment of life-threatening, invasive fungal infections. Expert Opin Pharmacother. 2013;14:2361-74.

2. Tacke D, Buchheidt D, Karthaus $M$, et al. Primary prophylaxis of invasive fungal infections in patients with haematologic malignancies. 2014 update of the recommendations of the infectious diseases working Party of the German Society for Haematology and oncology. Ann Hematol. 2014;93:1449-56.

3. De Pauw BE, Donnelly JP. Prophylaxis and aspergillosis - has the principle been proven? N Engl J Med. 2007;356:409-11.

4. Dekkers BG, Bakker $M$, van der Elst $K C$, et al. Therapeutic drug monitoring of Posaconazole: an update. Curr Fungal Infect Rep. 2016;10:51-61.
5. Patterson TF, Thompson GR 3rd, Denning DW, et al. Practice guidelines for the diagnosis and management of Aspergillosis: 2016 update by the Infectious Diseases Society of America. Clin Infect Dis. 2016;63:e1-e60.

6. Pappas PG, Kauffman CA, Andes DR, et al. Clinical practice guideline for the management of candidiasis: 2016 update by the Infectious Diseases Society of America. Clin Infect Dis. 2016:62:e1-50.

7. Marchetti O, Lamoth F, Mikulska M, et al. ECIL recommendations for the use of biological markers for the diagnosis of invasive fungal diseases in leukemic patients and hematopoietic SCT recipients. Bone Marrow Transplant. 2012;47:846-54.

8. FDA. 17 February 2009, accession date. Posaconazole. FDA briefing document. https://www.accessdata.fda.gov/drugsatfda_docs/nda/2006/ 022003s000_noxafil_medr.pdf. 2007.

9. Eiden C, Meniane JC, Peyriere $\mathrm{H}$, et al. Therapeutic drug monitoring of posaconazole in hematology adults under posaconazole prophylaxis: influence of food intake. Eur J Clin Microbiol Infect Dis. 2012;31:161-7.

10. Dolton MJ, Ray JE, Chen SC, et al. Multicenter study of posaconazole therapeutic drug monitoring: exposure-response relationship and factors affecting concentration. Antimicrob Agents Chemother. 2012;56:5503-10.

11. Chae H, Cho SY, Yu H, et al. Determination of posaconazole concentration with LC-MS/MS in adult patients with hematologic malignancy. Clin Chim Acta. 2015;450:220-6.

12. Jang SH, Colangelo PM, Gobburu JV. Exposure-response of posaconazole used for prophylaxis against invasive fungal infections: evaluating the need to adjust doses based on drug concentrations in plasma. Clin Pharmacol Ther-IF=7268. 2010;88:115-9.

13. Groll AH, Castagnola E, Cesaro $\mathrm{S}$, et al. Fourth European conference on infections in Leukaemia (ECIL-4): guidelines for diagnosis, prevention, and treatment of invasive fungal diseases in paediatric patients with cancer or allogeneic haemopoietic stem-cell transplantation. Lancet Oncol. 2014;15:e327-40.

14. Hoenigl M, Raggam RB, Salzer HJ, et al. Posaconazole plasma concentrations and invasive mould infections in patients with haematological malignancies. Int J Antimicrob Agents. 2012;39:510-3.

15. Lebeaux D, Lanternier F, Elie C, et al. Therapeutic drug monitoring of posaconazole: a monocentric study with 54 adults. Antimicrob Agents Chemother. 2009;53:5224-9.

16. Krishna G, AbuTarif $M$, Xuan $F$, et al. Pharmacokinetics of oral posaconazole in neutropenic patients receiving chemotherapy for acute myelogenous leukemia or myelodysplastic syndrome. Pharmacotherapy. 2008;28:1223-32.

17. Andes D, Pascua A, Marchetti O. Antifungal therapeutic drug monitoring: established and emerging indications. Antimicrob Agents Chemother. 2009; 53:24-34.

18. Jacobsen AA, Papo YB, Sarro R, et al. Posaconazole substitution for Voriconazole-associated phototoxic effects. JAMA Dermatol. 2016;152(7): 839-41.

19. Heinz WJ, Egerer G, Lellek $H$, et al. Posaconazole after previous antifungal therapy with voriconazole for therapy of invasive aspergillus disease, a retrospective analysis. Mycoses. 2013;56:304-10.

20. Cornely OA, Maertens J, Winston DJ, et al. Posaconazole vs. fluconazole or itraconazole prophylaxis in patients with neutropenia. N Engl J Med. 2007; 356:348-59

21. Ullmann AJ, Lipton $\mathrm{JH}$, Vesole $\mathrm{DH}$, et al. Posaconazole or fluconazole for prophylaxis in severe graft-versus-host disease. N Engl J Med. 2007;356:33547.

22. Cota GF, de Sousa MR, Fereguetti TO, et al. Efficacy of anti-leishmania therapy in visceral leishmaniasis among HIV infected patients: a systematic review with indirect comparison. PLoS Negl Trop Dis. 2013;7:e2195.

23. Higgins JP, Altman DG, Gotzsche PC, et al. The Cochrane Collaboration's tool for assessing risk of bias in randomised trials. BMJ. 2011;343:d5928.

24. De Pauw B, Walsh TJ, Donnelly JP, et al. Revised definitions of invasive fungal disease from the European Organization for Research and Treatment of Cancer/invasive fungal infections cooperative group and the National Institute of Allergy and Infectious Diseases mycoses study group (EORTC/ MSG) consensus group. Clin Infect Dis. 2008;46:1813-21.

25. Thorlund K, Devereaux PJ, Wetterslev J, et al. Can trial sequential monitoring boundaries reduce spurious inferences from meta-analyses? Int J Epidemiol. 2009:38:276-86

26. French CJ, Glassford NJ, Gantner D, et al. Erythropoiesis-stimulating agents in critically ill trauma patients: a systematic review and meta-analysis. Ann Surg. 2017;265:54-62. 
27. Wetterslev J, Thorlund K, Brok J, et al. Trial sequential analysis may establish when firm evidence is reached in cumulative meta-analysis. J Clin Epidemiol. 2008;61:64-75.

28. Thorlund K, Wetterslev J, Brok J et al. User manual for trial sequential analysis (TSA). Copenhagen: Copenhagen trial unit, Centre for Clinical Intervention Research. 2011. p. 115.

29. Varvaki Rados D, Catani Pinto L, Reck Remonti L, et al. The association between sulfonylurea use and all-cause and cardiovascular mortality: a meta-analysis with trial sequential analysis of randomized clinical trials. PLoS Med. 2016;13:e1001992.

30. Brok J, Thorlund K, Wetterslev J, et al. Apparently conclusive meta-analyses may be inconclusive-trial sequential analysis adjustment of random error risk due to repetitive testing of accumulating data in apparently conclusive neonatal meta-analyses. Int J Epidemiol. 2009;38:287-98.

31. Vanstraelen K, Colita A, Bica AM, et al. Pharmacokinetics of Posaconazole oral suspension in children dosed according to body surface area. Pediatr Infect Dis J. 2016;35:183-8.

32. Thakuria L, Packwood K, Firouzi A, et al. A pharmacokinetic analysis of posaconazole oral suspension in the serum and alveolar compartment of lung transplant recipients. Int J Antimicrob Agents. 2016;47:69-76.

33. Park WB, Cho JY, Park SI, et al. Effectiveness of increasing the frequency of posaconazole syrup administration to achieve optimal plasma concentrations in patients with haematological malignancy. Int J Antimicrob Agents. 2016;48(1):106-10.

34. Cornely OA, Duarte RF, Haider $\mathrm{S}$, et al. Phase 3 pharmacokinetics and safety study of a posaconazole tablet formulation in patients at risk for invasive fungal disease. J Antimicrob Chemother. 2016;71:718-26.

35. Hummert SE, Green MR. Therapeutic drug monitoring and dose adjustment of Posaconazole oral suspension in adults with acute myeloid leukemia. Ther Drug Monit. 2015;37:508-11.

36. Maertens J, Cornely OA, Ullmann AJ, et al. Phase 1B study of the pharmacokinetics and safety of posaconazole intravenous solution in patients at risk for invasive fungal disease. Antimicrob Agents Chemother. 2014;58(7):3610

37. Duarte RF, Lopez-Jimenez J, Cornely OA, et al. Phase 1b study of new posaconazole tablet for prevention of invasive fungal infections in high-risk patients with neutropenia. Antimicrob Agents Chemother. 2014;58:5758-65.

38. Desplanques PY, Burlacu $R$, Poinsignon $V$, et al. Factors influencing posaconazole plasmatic concentrations in patients presenting with acute myeloid leukemia. Med Mal Infect. 2014;44:174-9.

39. Bourdelin M, Grenouillet F, Daguindau E, et al. Posaconazole prophylaxis in neutropenic patients with hematological malignancies: limits in clinical practice. Med Mycol. 2014;52:728-35.

40. Gross BN, Ihorst $G$, Jung $M$, et al. Posaconazole therapeutic drug monitoring in the real-life setting: a single-center experience and review of the literature. Pharmacotherapy. 2013;33:1117-25.

41. Cattaneo C, Borlenghi E, Panzali A, et al. Impact of posaconazole prophylaxis on invasive fungal infection during acute myeloid leukemia induction therapy: correlation with posaconazole serum levels. Blood. 2013;122(21): 3484.

42. Tonini J, Thiebaut A, Jourdil JF, et al. Therapeutic drug monitoring of posaconazole in allogeneic hematopoietic stem cell transplantation patients who develop gastrointestinal graft-versus-host disease. Antimicrob Agents Chemother. 2012;56:5247-52.

43. Ross $A L$, Slain $D$, Cumpston $A$, et al. Evaluation of an alternative posaconazole prophylaxis regimen in haematological malignancy patients receiving concomitant stress ulcer prophylaxis. Int J Antimicrob Agents. 2012;40:557-61.

44. Pavan L, Loregian A, Quinto AM, et al. Posaconazole prophylaxis in patients undergoing chemotherapy for acute myeloid leukemia: a single center experience of therapeutic drug monitoring. Blood. 2012;120(21):2595.

45. Shields RK, Clancy CJ, Vadnerkar A, et al. Posaconazole serum concentrations among cardiothoracic transplant recipients: factors impacting trough levels and correlation with clinical response to therapy. Antimicrob Agents Chemother. 2011;55:1308-11.

46. Fanci $R$, Fallani $\mathrm{S}$, Bencini $\mathrm{S}$, et al. Therapeutic drug monitoring (TDM) of posaconazole in acute leukemia patients: preliminary results of a monocentric experience. Haematologica. 2011;96:107-8.

47. Bryant AM, Slain D, Cumpston A, et al. A post-marketing evaluation of posaconazole plasma concentrations in neutropenic patients with haematological malignancy receiving posaconazole prophylaxis. Int J Antimicrob Agents. 2011;37:266-9.

48. Welzen ME, Bruggemann RJ, Van Den Berg JM, et al. A twice daily posaconazole dosing algorithm for children with chronic granulomatous disease. Pediatr Infect Dis J. 2011;30:794-7.

49. Sengar M, Dsouza S, Deshpande R, et al. Therapeutic drug monitoring of posaconazole in adult acute myeloid leukemia (AML) patients receiving posaconazole prophylaxis during induction: experience from a center with high invasive fungal infection (IFI)burden. Blood. 2016;128(22):4005.

50. Döring M, Cabanillas Stanchi KM, Queudeville M, et al. Efficacy, safety and feasibility of antifungal prophylaxis with posaconazole tablet in paediatric patients after haematopoietic stem cell transplantation. J Cancer Res Clin Oncol. 2017;143:1281-92.

51. Liebenstein TK, Widmer KM, Fallon MJ. Retrospective analysis of goal drug level attainment of posaconazole for invasive fungal infection prophylaxis in patients with acute myeloid leukemia pre- and post-switch to tablet formulation. J Oncol Pharm Pract. 2017. https://doi.org/10.1177/ 1078155217722405

52. Tverdek FP, Heo ST, Aitken SL, et al. Real-life assessment of the safety and effectiveness of the new tablet and intravenous formulations of posaconazole in the prophylaxis of invasive fungal infections via analysis of 343 courses. Antimicrob Agents Chemother. 2017;61. https://doi.org/10. 1128/AAC.00188-17.

53. Conte JE Jr, Golden JA, Krishna G, et al. Intrapulmonary pharmacokinetics and pharmacodynamics of posaconazole at steady state in healthy subjects. Antimicrob Agents Chemother. 2009;53:703-7.

54. Winston D, Bartoni K, Territo M, et al. Efficacy and safety of standard longterm posaconazole antifungal prophylaxis in allogeneic stem-cell transplant recipients. Clin Microbiol Infect. 2010;16:S3.

55. Walsh TJ, Raad I, Patterson TF, et al. Treatment of invasive aspergillosis with posaconazole in patients who are refractory to or intolerant of conventional therapy: an externally controlled trial. Clin Infect Dis. 2007;44:2-12.

56. Luong ML, Al-Dabbagh M, Groll AH, et al. Utility of voriconazole therapeutic drug monitoring: a meta-analysis. J Antimicrob Chemother. 2016;71:1786-99.

57. Jin $\mathrm{H}$, Wang $\mathrm{T}$, Falcione BA, et al. Trough concentration of voriconazole and its relationship with efficacy and safety: a systematic review and metaanalysis. J Antimicrob Chemother. 2016;71:1772-85.

58. Zhao YJ, Khoo AL, Tan G, et al. Fluconazole, Itraconazole, Posaconazole and Voriconazole in invasive fungal infection prophylaxis: network meta-analysis and Pharmacoeconomic evaluation. Antimicrob Agents Chemother. 2015; 60(1):376-86

59. Shoham S, Ostrander D, Marr K. Posaconazole liquid suspension in solid organ transplant recipients previously treated with voriconazole. Transpl Infect Dis. 2015;17:493-6.

\section{Submit your next manuscript to BioMed Central and we will help you at every step:}

- We accept pre-submission inquiries

- Our selector tool helps you to find the most relevant journal

- We provide round the clock customer support

- Convenient online submission

- Thorough peer review

- Inclusion in PubMed and all major indexing services

- Maximum visibility for your research

Submit your manuscript at www.biomedcentral.com/submit
Biomed Central 